\title{
Quadrivalently Doped Hematite Thin Films for Solar Water Splitting
}

\author{
J. D. Desai ${ }^{1,2}$, P. K. Baviskar ${ }^{1 *}$, K. N. Hui ${ }^{3}$ and H. M. Pathan ${ }^{1 *}$
}

Hydrogen production using sun light is considered to be one of the most promising alternatives to fossil fuel-derived energy technology. This review presented the study on the photo-electrochemical (PEC) response of hematite $\left(\alpha-\mathrm{Fe}_{2} \mathrm{O}_{3}\right)$ by quadrivalent doping results in n-type conductivity. In general, dopants improve the conductivity of hematite thin films. The improved conductivity brought on the incorporation of the dopant is most likely from the n-type lattice substitution of $\mathrm{Fe}^{3+}$ by tetravalent ions, such as $\mathrm{Si}^{4+}$, resulting in a higher electron concentration. This supplementation may be carried out by employing a Tandem cell configuration. This induces a proper direction for the future course of investigations that may lead to an economic, renewable method for environment-friendly hydrogen production.

Keywords: Hematite; Doping; Water splitting; Photochemistry; Efficiency

Received 29 November 2018, Accepted 20 December 2018

DOI: $10.30919 /$ esee 8 c208

\section{Introduction}

Thrust areas of today's research are focused on the energy crisis and environmental pollution related topics. The adverse impacts of various industries on the environment have been well conceived by society. In the $21^{\text {st }}$ century, human beings seek to overcome the two major challenges of energy and the environment. The carbon-containing energy carrier's causes environmental pollution and energy crisis that can be addressed simultaneously in a promising way by hydrogen. The gravimetric energy density of hydrogen is $\sim 140 \mathrm{MJ} / \mathrm{kg}$, which is three times superior to that of gasoline. Moreover, hydrogen as a fuel can be stored \& transported; it reacts with oxygen in a fuel cell to generate electricity in an environmentally benign manner, with water as the only byproduct. Although hydrogen being a clean energy carrier, almost all ( $\sim 95 \%)$ hydrogen is produced by the steam reforming of methane; which produces undesirable products, such as carbon monoxide and dioxide. Therefore, a cost effective and efficient method of hydrogen production from renewable, carbon free sources is an important step. Water and solar energy both are renewable, carbon free and abundant. In order to develop new strategies for hydrogen production, numerous strategies have been attempted and the photo-electrochemical (PEC) approach is one receiving focal attention in this cross disciplinary research area ${ }^{1-7}$. A PEC cell consists of anode and cathode, on which electron transfer take place by redox chemical reactions. One of the electrodes should be a semiconductor that absorbs solar energy. A PEC cell for hydrogen generation typically consists of a semiconductor

${ }^{I}$ Advanced Physics Laboratory, Department of Physics, Savitribai Phule Pune University, Pune-411007, India

${ }^{2}$ STES's N.B. Navale College of Com. \& Science Kusgaon (BK) Lonavala, Maval, Pune-410401, India

${ }^{3}$ Institute of Applied Physics and Materials Engineering, University of Macau, Avenida da Universidade, Macau

*E-mail: pkbaviskar@physics.unipune.ac.in; habib.pathan@gmail.com photo-anode (usually referred to as a photo-electrode, PE) and platinum as a cathode. Light irradiation with the photon energy equal to or exceeding the band-gap energy of the semiconductor PE, electrons will be promoted from the valence band to the unoccupied conduction band, leaving holes in the valence band. ${ }^{8}$ Solar hydrogen generation involves the use of a suitable photo-anode capable of producing a sufficient voltage and current which is necessary to drive the water splitting reaction. The photo-anode should be cost-effective and stable (given in detail in section 1.3.5). The first relatively efficient material discovery was $\mathrm{TiO}_{2} .{ }^{9}$ A large number of studies, on many materials have since been conducted till date. Among a variety of candidates for the PE, semiconductor metal oxides namely $\mathrm{TiO}_{2}, \mathrm{ZnO}, \mathrm{WO}_{3}, \mathrm{Sn}_{3} \mathrm{O}_{4}$ and $\mathrm{Fe}_{2} \mathrm{O}_{3}$ have attracted considerable attention because of their superior chemical stability in an oxidative environment and low-cost. ${ }^{1,1-14}$ The weak visible light absorption is the major limitation for all wide band-gap semiconductors, such as $\mathrm{TiO}_{2}, \mathrm{ZnO}$ and $\mathrm{WO}_{3} .{ }^{8}$ Unfortunately, till today, there is no such material that can meet all the requirements simultaneously. Hematite $\left(\alpha-\mathrm{Fe}_{2} \mathrm{O}_{3}\right)$ has received considerable attention because of its advantages in context with abundance, low cost, an appropriate band gap suitable for visible light, nontoxicity, and electrochemical stability. ${ }^{15}$ In fact, hematite has been identified as an excellent candidate for photo-anodes in water splitting because it is earth-abundant, cost-effective, photo-electrochemically stable, and most importantly, has a desirable band gap of $2.3 \mathrm{eV}^{16,17}$

In case of nano-materials, effect of doping with metals or nonmetals has been well demonstrated in PEC studies. It has been proven that doping can narrow the band-gap energy, suppress electron-hole recombination, increase the conductivity of the semiconductor and modify the material structure in order to increase the effective surface area of nano-materials, which can all lead to enhanced PEC performance compared to pristine semiconductors. ${ }^{8}$ In this article, it is proposed to limit the aspect of quadrivalently-doped hematite films for PEC water splitting. The quest for new materials and methods has produced voluminous and valuable data. The dopant plays vital role with regard to the crystallite size, film thickness and electrical 
conductivity, ultimately affecting the material properties and quantum efficiency. Doping has been in practice traditionally, the desired properties for a pristine semiconductor can be tailored by the process of 'doping'. In case of hematite thin films for water cleavage, both p-type and n-type thin films have been attempted. In order to obtain p-type thin films, divalent dopants have been employed. For n-type, trivalent, quadrivalent, pentavalent and even hexavalent impurities have been used. The preparation method, dopants employed, post deposition treatment, characterizations, and finally the applications of PE for water splitting under illumination conditions differ according to the investigators; therefore the choice of dopant is crucial. Furthermore, the quantity of impurity to be added in the precursors is determined by trials. Authors could not find consolidated useful data for n-type hematite thin films employed for water cleavage by doping. Authors have attempted to provide detailed information on the doping of hematite with the relevant background focus on quadrivalent doping, so that doped hematite PE could be well understood as a stable, economical and commercially viable PE to achieve the long sought of goal of many nations of attaining the hydrogen economy.

\subsection{Hydrogen as Energy Carrier and Fuel}

Owing to day by day depletion in the fossil fuel reserves, hydrogen has emerged as the most promising alternative fuel for the new energy economy, and there are major driving forces for the replacement of gasoline fossil fuel by hydrogen. ${ }^{18}$ (a) Price: Naturally, the oil price is rising due to falling reservoirs, whereas that of hydrogen is likely to be decrease. (b) Energy density: Hydrogen is a fuel with the highest energy capacity/mass (120.7 kJ/gm). (c) Pollution: During combustion, the absence of pollution is suitable for hydrogen operated vehicles. (d)

Insecure resources: Fossil fuel reserves are in a few oil rich countries that are in politically uncertain regions. (e) Location of Pollution: Urban pollution can be reduced by the removal of power plants to areas of lower populations. Owing to its environmental and economic benefits ${ }^{19}$ along with the anticipated energy security, the hydrogen economy has become a long-term goal of many nations.

Hydrogen is the lightest and first simplest atom (one proton and one electron) with an atomic number 1. Although it is abundant in the universe, very little hydrogen gas is present in the Earth's atmosphere. Hydrogen is locked up in huge quantities in water $\left(\mathrm{H}_{2} \mathrm{O}\right)$, hydrocarbons (such as methane, $\mathrm{CH}_{4}$ ), and other organic matter. The efficient production of hydrogen from these compounds is one of the challenges for the scientific community. Presently, the steam reforming of methane, i.e., natural gas, accounts for approximately $95 \%$ of the hydrogen produced in the United States. Almost all of the approximately 9 million tons of hydrogen produced each year are used for refining petroleum, treating metals, producing fertilizers, and processing foods. Since the 1950s, hydrogen has been used by NASA for space flights.

Hydrogen can be produced from a range of sources; however, hydrogen production from renewable sources is highly attractive. The most important renewable source of energy is the sun, in which an amount of energy equal to the total yearly human consumption is shone on planet Earth in just 10 minutes but less than $2 \%$ of the world's energy demand is harnessed due to the lack of suitable materials. Hydrogen generated from water using renewable sources of energy from the sun can resolve the problem of fuel availability, which is completely environmentally safe and green fuel for the future. ${ }^{20}$

Hydrogen has a potential to meet the requirements of a clean and non-fossil fuel if it can be produced by using the world's most abundant energy source (sun). The development of a clean, efficient and cost effective system for conversion solar energy and its storage is one of the challenges for solving the global energy problem. A large gap still exists between the present global energy consumption (around 13 tera-watts, TW), the use of solar energy to supply the world's energy demand $(<2$ $\%$ ), and the enormous untapped potential of the sun (120,000 TW). ${ }^{21}$ The realization of a solar hydrogen economy requires addressing the key techno-scientific challenges. One major issue is the need to develop highly efficient photoactive materials capable of harvesting and converting solar energy into stored chemical energy, i.e., hydrogen. ${ }^{22}$

\subsection{Splitting of Water under the Action of Light}

In biological photosynthesis, plants transform water and carbon dioxide in the presence of light to oxygen and carbohydrates according to the following reaction:

$$
6 \mathrm{CO}_{2}+6 \mathrm{H}_{2} \mathrm{O} \rightarrow \mathrm{C}_{6} \mathrm{H}_{12} \mathrm{O}_{6}+6 \mathrm{O}_{2}
$$

In effect, $\mathrm{H}_{2} \mathrm{O}$ is split into $\mathrm{H}_{2}$ and $\mathrm{O}_{2}$, where the hydrogen is not in the free gaseous form but bound by carbon.

Artificial photosynthesis is represented by the following equation:

$$
2 \mathrm{H}_{2} \mathrm{O} \rightarrow \mathrm{O}_{2}+2 \mathrm{H}_{2}
$$

and is the light-driven splitting of water into $\mathrm{H}_{2}$ and $\mathrm{O}_{2}$. Eqn. (2), which has been called the 'holy grail' in chemistry. 23

The PEC path to water splitting involves separating the oxidation and reduction processes into two half-cell reactions. ${ }^{24}$ Equations (3) and (4) show the half-cell reactions with their corresponding standard reduction potential, $\mathrm{E}^{\circ}$, with respect to the standard hydrogen electrode (SHE):

$$
\begin{gathered}
\text { Oxidation: } 2 \mathrm{H}_{2} \mathrm{O} \rightarrow \mathrm{O}_{2}+4 \mathrm{H}^{+}+4 \mathrm{e}^{-} \\
\mathrm{E}^{\circ}=1.23 \mathrm{~V} \text { vs. SHE } \\
\text { Reduction: } 2 \mathrm{H}^{+}+2 \mathrm{e}^{-} \rightarrow \mathrm{H}_{2} \\
\mathrm{E}^{\circ}=0.00 \mathrm{~V} \text { vs. SHE } \\
\text { Overall: } 2 \mathrm{H}_{2} \mathrm{O} \rightarrow \mathrm{O}_{2}+2 \mathrm{H}_{2} \\
\Delta \mathrm{E}^{\circ}=-1.23 \mathrm{~V}
\end{gathered}
$$

Eqn. (5) shows the overall reaction and the corresponding $\Delta \mathrm{E}^{\circ}$. The negative $\Delta \mathrm{E}^{\circ}$ indicates that water splitting is not a thermodynamically spontaneous process. ${ }^{25}$ For the reaction to occur, $1.23 \mathrm{~V}$ must be provided externally. Theoretically, the minimum voltage required to split water at $25{ }^{\circ} \mathrm{C}$ is $1.23 \mathrm{~V}$, (under no chemical bias conditions) based on the Nernst equation, although realistically, a voltage greater than $1.5 \mathrm{~V}$ is needed due to electrode over-potentials. ${ }^{26}$ The over-potential is the potential barrier that must be overcome before the current can flow through the electrode/solution interface.

When hydrogen is used as a fuel and oxidized to release its heat chemically (burnt) or electrochemically (in hydrogen or air fuel cell), it produces water by consuming a 2:1 ratio of hydrogen and oxygen. Oxygen from the air (containing of about $20 \% \mathrm{O}_{2}$ ) can react with hydrogen; such that the hydrogen combines with oxygen to generate heat and water. Off course direct combination (ignition) of $\mathrm{H}_{2}$ and $\mathrm{O}_{2}$ leads to immediate energy release (explosion) in fact hydrogen is consumed by taking oxygen from air and the fuel cell is an electrochemical device that produces electricity without combustion by combining hydrogen and oxygen from air to produce water and heat. 
German Scientist G H Shoenbein discovered this later on "Fuel Cell" was first developed by William Grove, a Welsh judge with intense scientific curiosity in 1839. A typical fuel cell has following important parts as depicted in Fig. 1. It is similar to battery that can produce electricity almost indefinitely as long as they have fuel to use and can be recharged with fuel. It converts hydrogen and oxygen into electricity, heat, and water. Fuel cells can produce powers in the range of few milli watts to mega watts. A single fuel cell consists of an electrolyte sandwiched between two thin electrodes (a porous anode and cathode) Hydrogen, or a hydrogen-rich fuel, is supplied to the anode where a catalyst separates hydrogen's negatively charged electrons from positively charged ions (protons). At the cathode, oxygen combines with electrons and, in some cases, with species such as protons or water, resulting in water or hydroxide ions, respectively. Fig. 1 shows the schematic of typical alkaline fuel cell (AFC) and the electrochemical reactions can be represented as:

$$
\begin{gathered}
\text { Cathode: } \mathrm{O}_{2}+4 \mathrm{H}^{+}+4 \mathrm{e}^{-} \rightarrow 2 \mathrm{H}_{2} \mathrm{O} \\
\text { Anode: } 2 \mathrm{H}_{2} \rightarrow 4 \mathrm{H}^{+}+4 \mathrm{e}^{-} \\
\text {Overall: } 2 \mathrm{H}_{2}+\mathrm{O}_{2} \rightarrow 2 \mathrm{H}_{2} \mathrm{O}
\end{gathered}
$$

Normally single fuel cell is not sufficient for any purposeful practical application, instead the cell in stack are put to use. This electrochemical process does not produce air pollution and have higher energy conversion efficiency compared to conventional Carnot engine. ${ }^{27}$

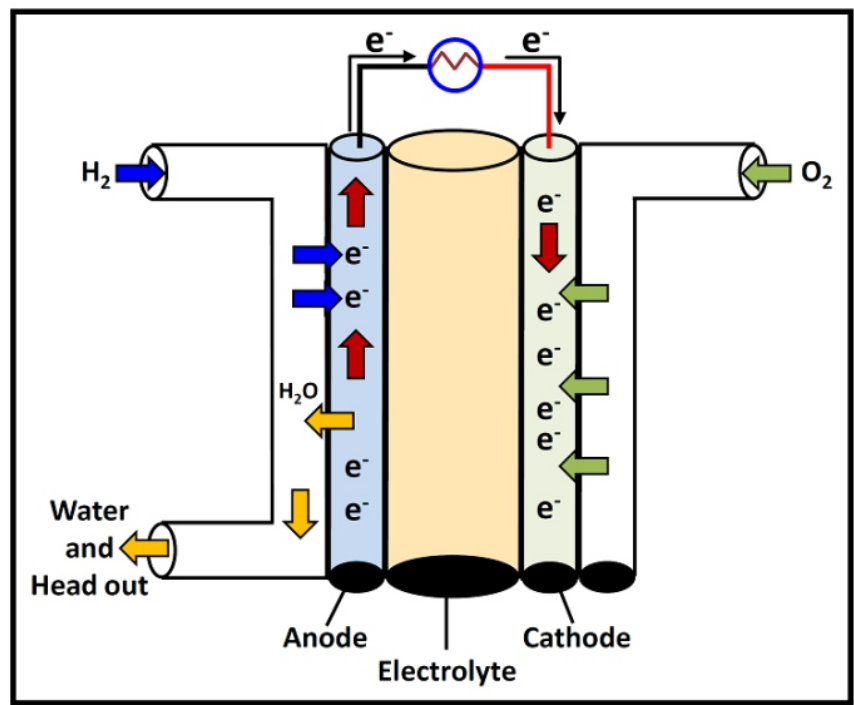

Fig. 1 Schematic of typical Alkaline Fuel Cell (AFC).

Fuel cells may be classified on the basis of ${ }^{28}$ :

A) Type of Electrolyte:

i. Alkaline Fuel cell (AFC) -operating temperature $50-200{ }^{\circ} \mathrm{C}$.

ii. Phosphoric Acid Fuel cell (PAFC)- operating temperature $170-200{ }^{\circ} \mathrm{C}$.

iii. Polymer Electrolytic Membrane Fuel Cell (PEMFC), Solid Polymer Fuel Cell (SPFC) and Proton Exchange Membrane Fuel cell (PEMFC)- operating temperature $60-200{ }^{\circ} \mathrm{C}$.

iv. Molten Carbonate Fuel Cell (MCFC)- operating temperature $600-700{ }^{\circ} \mathrm{C}$.

v. Solid Oxide Fuel Cell (SOFC)- operating temperature 900$1000{ }^{\circ} \mathrm{C}$.
Other classifications are also possible depending on

B) Fuel and oxidant and

C) Operating temperature

The efficiencies of the all types range from 40-60\%.

It is well understood that burning fossil fuels, such as coal and gasoline, usually releases $\mathrm{CO}, \mathrm{CO}_{2}$ and other pollutants, including sulfur dioxide into the atmosphere because these substances are usually present to varying extents in fossil fuels. On the other hand, if hydrogen can be obtained without producing greenhouse gases or other pollutants, ${ }^{29}$ then it would be a better fuel than fossil fuels.

\subsection{Semiconductor Electrochemistry}

Two materials with different conduction mechanisms, such as a semiconductor and an electrolyte, can produce a PEC device. The first observation of a photovoltaic effect (Becquerel, 1839) was in fact a PEC system. When a semiconductor is dipped in a solution, charge transfer takes place at the interface because of the difference in the electron affinity or electrochemical potential of the two phases. The net result is the formation of space charge regions at the surface of the semiconductor and in the electrolyte. If the semiconductor electrode absorbs radiation, electrons move towards the bulk of the n-type semiconductor, whereas holes move towards the surface and are injected into the electrolyte. Excited electrons can pass to the second electrode, which is connected to the first electrode through connecting conductive wires. The second electrode may be metallic or made of another type (p-type) semiconductor. The combination of two such electrodes immersed in an electrolyte solution forms the basis of a PEC cell. If an aqueous electrolyte is chosen, the reaction of water oxidation on the semiconductor anode and the reaction of hydrogen reduction on the cathode can take place, resulting in the photo-electrolysis of water (i.e. radiation-driven water splitting or solar water cleavage). ${ }^{30}$ The concept of PEC hydrogen generation based on the splitting of a water molecule on the surface of a photo-electrode (PE) is well illustrated in Fig. 2. The figure shows the basic components of a PEC circuit for water photolysis with the usual notations. An essential part of the device for hydrogen generation using solar energy is a semiconducting PE. In the case of photo-anode, the PE conventionally consists of an n-type semiconductor. Exposure to light results in intrinsic ionization over the band gap, leading to the formation of an electron-hole pair:

$$
2 \mathrm{~h} \rightarrow 2 \mathrm{e}^{*}+2 \mathrm{~h}
$$

where $\mathrm{h}$ is the light quantum, $\mathrm{e}^{*}$ is an electron and $\mathrm{h}$ is an electron hole. The excess minority charge carriers (electron holes) give rise to a photo-voltage, resulting in the splitting of a water molecule into hydrogen ions and gaseous oxygen as follows:

$$
2 \mathrm{~h}+\mathrm{H}_{2} \mathrm{O} \text { (liquid) } \rightarrow 2 \mathrm{H}+1 / 2 \mathrm{O}_{2} \text { (gas) }
$$

Gaseous oxygen evolves at the photo-anode and hydrogen ions migrate to the cathode through the electrolyte (internal circuit), where the reduction of hydrogen ions to gaseous hydrogen takes place as follows:

$$
2 \mathrm{H}+2 \mathrm{e}^{*} \rightarrow \mathrm{H}_{2} \text { (gas) }
$$

The overall reaction is:

$$
2 \mathrm{hv}+\mathrm{H}_{2} \mathrm{O} \text { (liquid) } \rightarrow \mathrm{H}_{2} \text { (gas) }+1 / 2 \mathrm{O}_{2} \text { (gas) }
$$




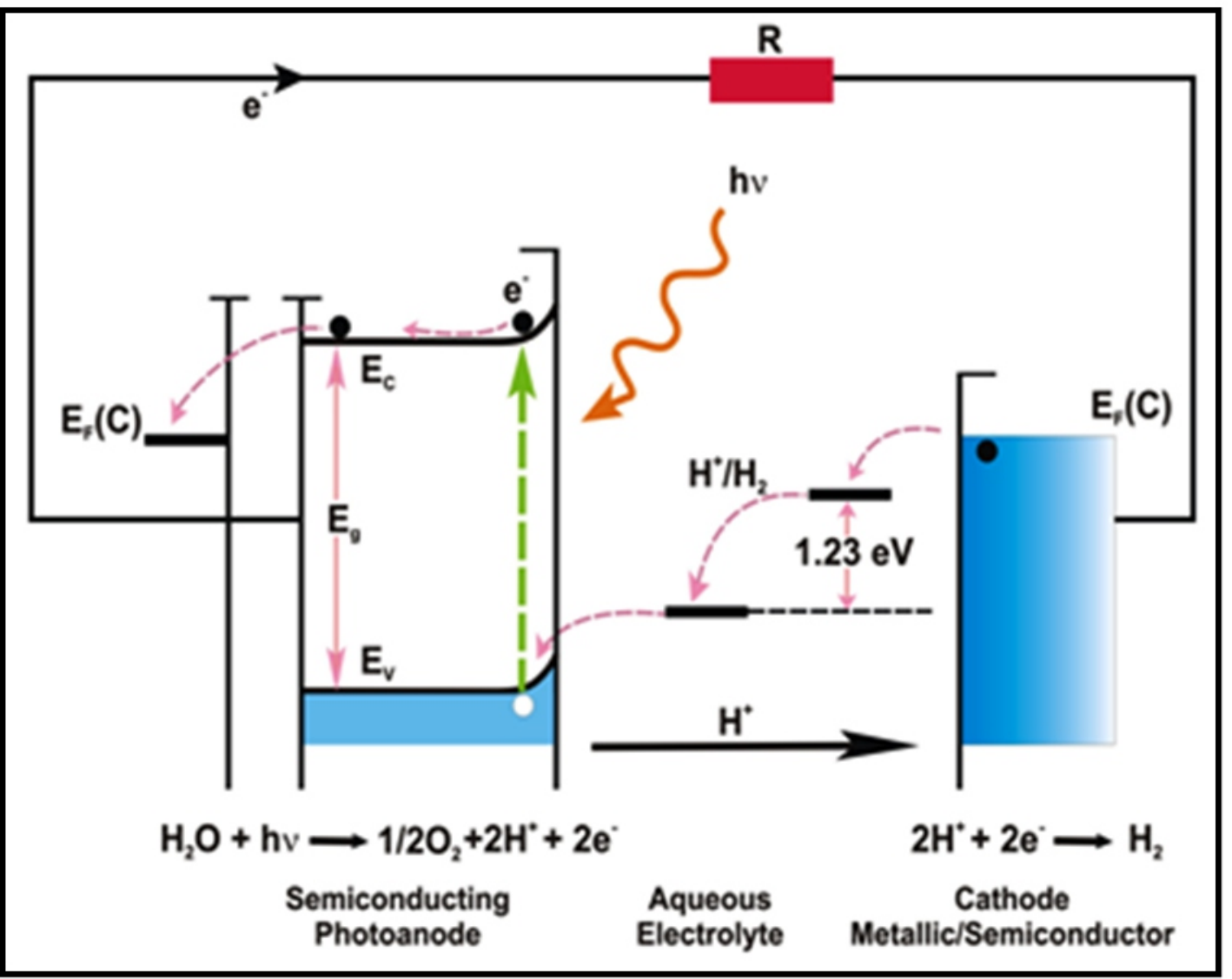

Fig. 2 Electrical circuit illustrating charge transfer within a PEC cell formed with a semiconducting photo-anode and metallic cathode.

Reaction takes place only when the E.M.F. of PEC is greater than or equal to $1.23 \mathrm{~V}$ per electron transferred. To use a semiconductor and carry out this reaction with light, the PE must absorb incident light with photon energies $>1.23 \mathrm{eV}$ (equal to wavelengths of $1000 \mathrm{~nm}$ and shorter) and convert the energy to $\mathrm{H}_{2}$ and $\mathrm{O}_{2}$ ) This process must generate two electron-hole pairs per molecule of $\mathrm{H}_{2},\{(2 \times 1.23 \mathrm{eV})=$ $2.46 \mathrm{eV}\} 2.46 \mathrm{eV}$ or four electron-hole pairs per molecule of $\mathrm{O}_{2}\{(4 \times$ $1.23 \mathrm{eV})=4.92 \mathrm{eV})\}^{26}$

Photo-electrolysis is the general term used to describe semiconductor-based PEC water splitting. For that purpose, materials that can drive the water splitting reaction upon light absorption are necessary. Three fundamental requirements should be met by any system harvesting and converting solar energy into chemical energy: i) the photo-response of the system must optimally match the solar spectrum; ii) photo-excited charges must be separated efficiently to prevent recombination; and iii) the charges must have sufficient energy to carry out the desired chemical reactions, such as water splitting. ${ }^{31}$ The realization of water splitting can be achieved by three distinct approaches, are as follows:

\subsubsection{Photovoltaic (PV) Approach:}

Photo-electrolysis can be accomplished using photovoltaic modules directly connected to electrolysis and/or catalytic electrodes. Water splitting cells with direct semiconductor/liquid contacts are attractive because they avoid rigorous fabrication and systems costs involved with the use of separate electrolysers wired to $\mathrm{p}-\mathrm{n}$ junction solar cells. ${ }^{26}$ The basic principle behind this is the decrease in electrochemical water splitting potential with increasing temperature. Solar radiation is used to generate the necessary potential by illuminating photovoltaic cells as well as for the heat source to facilitate water electrolysis. ${ }^{31}$

\subsubsection{Semiconductor-liquid junctions (SCLJ) approach:}

For this, the arrangement of a semiconductor PE and metal cathode are made in an aqueous solution. When the PE is illuminated, water splitting takes place because of oxidation into $\mathrm{O}_{2}$ or reduction into $\mathrm{H}_{2}$ of water.

\subsubsection{The combination of $P V \& S C L J$ :}

The supplementary bias for hydrogen evolution on a metallic cathode is provided by a solar cell, leading to a PV \& SCLJ approach for overall water splitting. All three approaches for water photo-electrolysis have their own merits and demerits, arising from the approach itself as well as/or from the PE used. Many leading researchers in the field state that research should now be focused on the most promising approach for water splitting, being a PV cell combined with a semiconductor- based PEC cell, i.e., PV \& SCLJ approach. ${ }^{26}$

Among the three possible approaches, to achieve commercially viable technology, the required photo-conversion efficiency should be at least $10 \%{ }^{2}$ (efficiency considerations will be taken into account in section 1.3.6). The upper limit of the photo-conversion efficiencies for the three types of PEC cells has been derived by Weber and Dignam. Accordingly, an efficiency of $18 \%$ can be achieved only with the tandem cell, i.e. PEC cell coupled with a PV cell is employed. ${ }^{32}$

\subsubsection{Comparison of Photo-catalytic and PEC, artificial photosynthesis:}


The difference needs to be made between the two different approaches of artificial photosynthesis: The photo-catalytic water splitting approach uses a well dispersed material in pure water and produces hydrogen and oxygen homogeneously throughout the solution using both inorganic colloid materials ${ }^{33,34}$ and molecular complexes. ${ }^{35}$ In contrast, PEC systems use photoactive materials as the PE. Similar to conventional water electrolysis, an oxidative reaction $\left(\mathrm{O}_{2}\right.$ evolution $)$ occurs at the anode, reduction $\left(\mathrm{H}_{2}\right.$ evolution) takes place at the cathode and a closed circuit is formed through an aqueous electrolyte between the electrodes. One or both of the electrodes can be a photoactive semiconductor, in which a space-charge (depletion) layer is formed at the semiconductor/liquid junction (SCLJ). Under the illumination of light, photo-generated charge carriers are separated by the space-charge field and the minority carriers travel to the SCLJ to perform one half of the water splitting reaction. The great advantage of the PEC approach is that it allows the production and hence the $\mathrm{H}_{2}$ and $\mathrm{O}_{2}$ collected to be separated spatially.

\subsubsection{Ideal Photoelectrode Requirements: $:^{36,37}$}

i) Band gap: PEs should have the appropriate band gap for solar absorption.

ii) Low electrical resistance for efficient charge transfer.

iii) Flat-band potential should be higher than the redox potential of $\mathrm{H}^{+} / \mathrm{H}_{2}$ pair.

iv) Schottkey barrier is required for effective charge separation.

v) Energy conversion efficiency (ECE), which is defined as ratio of the amount of energy $\mathrm{O} / \mathrm{P}$ (=generated electrical or chemical energy) to the energy I/P (incident solar energy), must be greater than $10 \%$. The recently reported maximum efficiency was only $8.5 \%$.

vi) Stability: resistant to corrosion and photo-corrosion in an aqueous medium.

vii) Available abundantly in earth crust (off course it is again affiliated to market price).

viii) Cost effective and ease to fabricate, and the device must be maintenance free as far as possible.

ix) The cost of the device and infrastructure must be comparable to other competing technologies.

As mentioned earlier, to date, there is no such material that can meet all the above requirements simultaneously.

\subsubsection{Efficiency Considerations:}

The efficiency of a PEC cell is limited because of charge carrier excitation and transfer processes within the PE. The Incident Photon Conversion Efficiency (IPCE), also called as External Quantum Efficiency (EQE), is the accepted measure for calculating the conversion efficiency. This is the ratio of incident photons to photocurrent flowing between working and counter electrodes. ${ }^{38}$ For an IPCE of $100 \%$, there will be one photoelectron produced per incident photon.

The IPCE is calculated by using the equation,

$$
\operatorname{IPCE}=1240\left(\mathrm{I}_{\mathrm{p}}(\lambda) / \mathrm{P}(\lambda) \lambda\right)
$$

where $\mathrm{I}_{\mathrm{p}}(\lambda)$ and $\mathrm{P}(\lambda) \lambda$ are the photocurrent density and incident light intensity at wavelength, $\lambda$, respectively. Another way to calculate the efficiency is the absorbed photons to electron conversion efficiency (APCE) or Internal Quantum Efficiency (IQE). This gives the number of charge carriers collected per absorbed photon. Unlike IPCE, it considers the losses in the conversion process. By knowing the absorbance, A of the PE, the APCE can be calculated by using equation (12)

$$
\mathrm{APCE}=(\mathrm{IPCE}) / 1-10^{-\mathrm{A}}
$$

\section{2. $\alpha-\mathrm{Fe}_{2} \mathrm{O}_{3}$ (Hematite) Thin Films}

There are as many as 16 iron oxide phases. ${ }^{39}$ They are abundant in the earth's crust, and are widespread in soil and rocks. They can be synthesized in pure, mixed oxides and doped form. Machala el al. describes the polymorphous transformations of nano-metric iron (III) oxides, ${ }^{40}$ because of the great interest in iron oxides, particularly in nano-sized form, from both fundamental and application reasons.

The most common oxides are hematite $\left(\alpha-\mathrm{Fe}_{2} \mathrm{O}_{3}\right)$, maghemite $(\gamma$ $\mathrm{Fe}_{2} \mathrm{O}_{3}$ ) and magnetite $\left(\mathrm{Fe}_{3} \mathrm{O}_{4}\right)$. These have different electrical, magnetic, electro-optical, and chemical properties. ${ }^{41}$ Among these three common iron oxides, hematite, $\alpha-\mathrm{Fe}_{2} \mathrm{O}_{3}$, which derived its name from Latin word, haima, means blood, due to its red color, is most well-known. On the other hand, it appears as black or grey when it is formed of large and coarse crystalline grains. Hematite is the thermodynamically stable crystallographic phase of iron (III) oxide, and is abundant in the earth's crust, low cost and non-toxic.

Hematite $\left(\alpha-\mathrm{Fe}_{2} \mathrm{O}_{3}\right)$ is isostructural with corundum $\left(\alpha-\mathrm{Al}_{2} \mathrm{O}_{3}\right)$ and eskolite $\left(\alpha-\mathrm{Cr}_{2} \mathrm{O}_{3}\right)$. The unit cell is hexagonal with $\mathrm{a}=5.034 \AA$ and $\mathrm{c}=$ $13.75 \AA$ with six formula units per unit cell. This may be indexed in the rhombohedral system and the crystal structure belongs to the $R 3 C$ space group with $\alpha=55^{\circ} 17^{\prime}$ and $\mathrm{a}=5.42 \AA$, with two formula units per unit cell. ${ }^{42,43}$ Fig. 3 shows the schematic structure of $\mathrm{Fe}$ and $\mathrm{O}$ bonding.

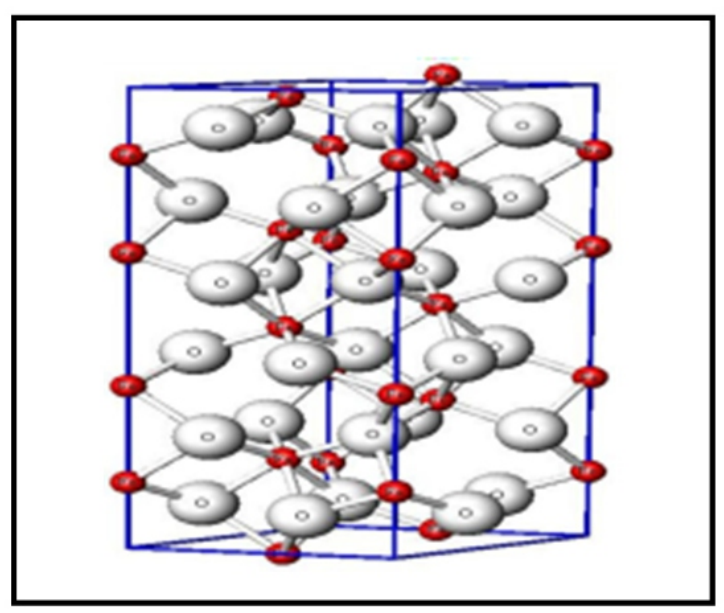

Fig. 3 Bonding of Fe-O (Red spheres Fe, Grey spheres O). ${ }^{44}$

Hematite has an optical band gap of $\sim 2 \mathrm{eV}$, good chemical stability and appropriate valence band edges (i.e. $+1.6 \mathrm{~V} / \mathrm{SCE}$ at $\mathrm{pH}=14$ ) for photo-induced oxygen evolution from water. Because it satisfies the majority of the requirements of an ideal PE (already mentioned in section 1.3.5), it has been tested as an electrode in (PEC) cell for energy conversion due to its proper band gap. ${ }^{41}$ The actual applications in devices require iron oxide in thin film form. In hematite, Fe is in the trivalent state. X-ray photoelectron spectroscopy (XPS) provides vital information regarding the oxidation states of the species in the film deposited. ${ }^{45} \mathrm{Fe}^{3+}$ has an electronic configuration of $1 \mathrm{~s}^{2} 2 \mathrm{~s}^{2} 2 \mathrm{p} 63 \mathrm{~s}^{2} 3 \mathrm{p}^{6}$ $3 d^{5}$ (while $\mathrm{Fe}^{2+}$ is $1 \mathrm{~s}^{2} 2 \mathrm{~s}^{2} 2 \mathrm{p}^{6} 3 \mathrm{~s}^{2} 3 \mathrm{p}^{6} 3 \mathrm{~d}^{6}$ ). Therefore, the electrons in $\mathrm{d}$ orbital and their characteristics are those which define the electrical properties of iron oxides. The region of space occupied by either a single electron or a pair of electrons is called an orbital. According to Pauli's exclusion principle, no two electrons can have the same spins in an orbital. Therefore, $\mathrm{Fe}^{3+}$ has 5 different $\mathrm{d}$ orbitals that are oriented at 5 


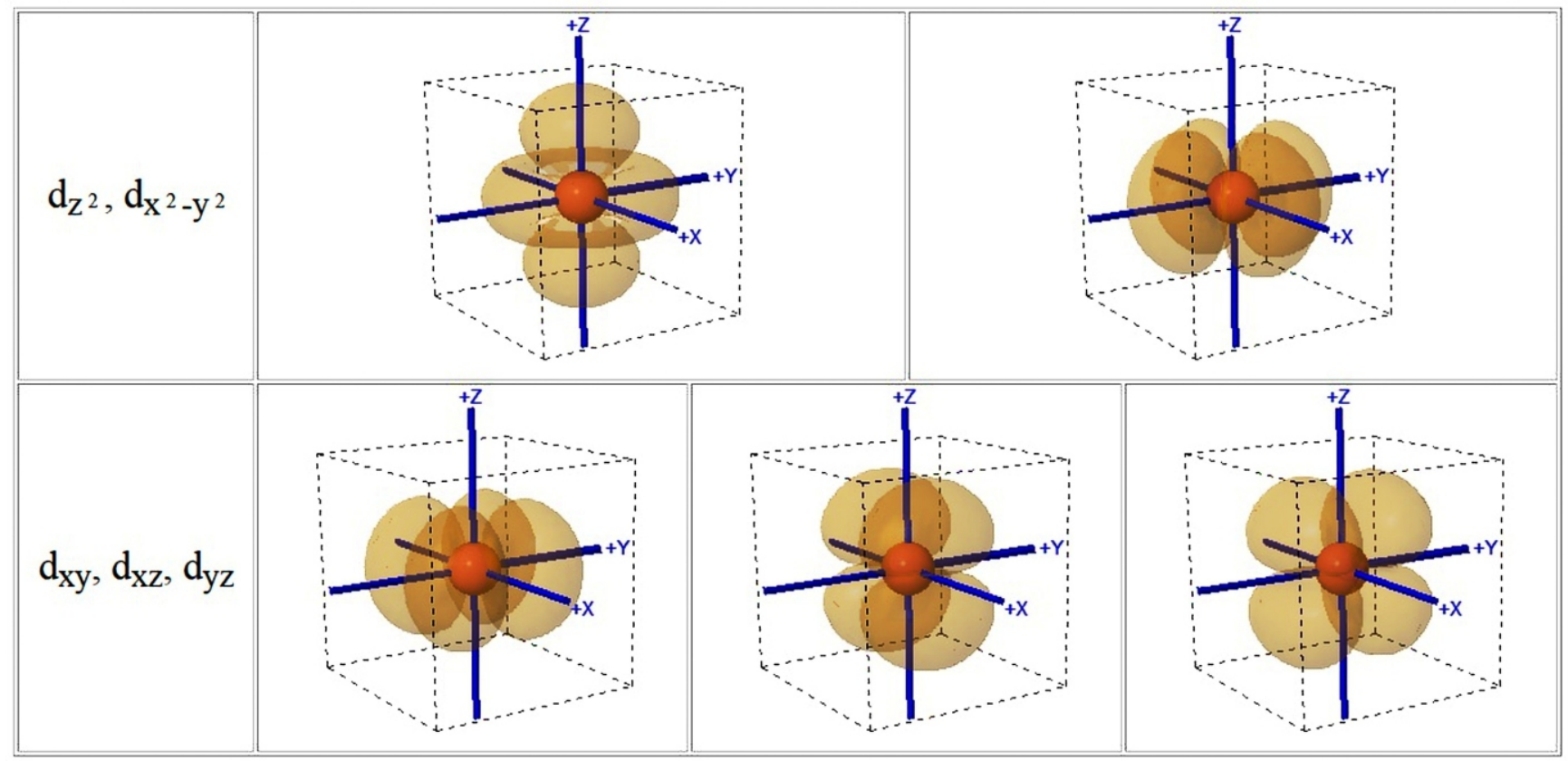

Fig. $4 \mathrm{dx}^{2}-\mathrm{y}^{2}, \mathrm{dz}^{2}, \mathrm{dxy}, \mathrm{dyz}$, and dxz orbitals. ${ }^{46}$

different orientations in space. The orbital's lobes are those regions, where the electron density is at a maximum. The 5 orbitals have been grouped into two set of orbitals according to the direction of their lobes. Three orbitals, namely dxy, dyz and dxz, each has four lobes that are directed between the coordinate axes of the nucleus. The second set of orbitals, $\mathrm{dx}^{2}-\mathrm{y}^{2}$ and $\mathrm{dz}^{2}$, have their lobes oriented along the axis. In crystal field terminology, the charges are considered point charges; the $\mathrm{dx}^{2}-\mathrm{y}^{2}, \mathrm{dz}^{2}, \mathrm{dxy}, \mathrm{dyz}$, and $\mathrm{dxz}$ orbitals have been placed in pictorial presentation, as depicted in Fig. 4.

In iron oxides and hydroxides, Fe ions are coordinated to negatively charged $\mathrm{O}^{2-}$ and $\mathrm{OH}^{-}$ions. Therefore, due to the electrostatic field of the coordination, the $\mathrm{d}$ orbitals of $\mathrm{Fe}$ do not show equal energies, unlike that in their ground state. Stoichiometric hematite is an $\mathrm{n}$ type semiconductor. In n-type hematite, the conduction band comprises of empty $\mathrm{Fe}^{3+} \mathrm{d}$ orbitals, whereas the valence band is composed of two full Fe 3d ligand field orbitals and some admixture from the oxygen antibonding $2 p$ orbitals. ${ }^{47}$

The PEC performance of hematite photo-electrodes is much below its theoretical maximum of $12.9 \%$, which has been attributed to its short minority carrier diffusion length and rapid decrease in the absorption cross-section of the material for wavelengths approaching the band gap. In addition, the problem of the conduction band edge of hematite is too positive to reduce water to hydrogen directly; this can be overcome by applying a bias, which can be provided by another solar cell in a tandem configuration. Several approaches have been used to overcome the low mobility for improving the PEC performance of hematite PEs. These can be divided into two types: (a) Doping: for improving the conductivity of hematite and (b) Nano-structuring: to increase the surface area and reduce the distance that the photogenerated charge carriers need to travel for collection. Attempts have been made to modify the film morphology to overcome the short hole diffusion length $(<5 \mathrm{~nm}){ }^{48}$

The aim of this contribution is to overview the recent developments in improving the performance of hematite PE with a focus on doping; particularly n-type. The important results of numerous attempts of various workers will be presented as a summary w.r.t. PE synthesis methods, precursors/starting materials/chemicals employed, important preparative parameters, post deposition treatments, characterizations, and efficiency achieved. Therefore, at the end, it may be possible to discuss the merits and limitations involved therein. Hematite in the pure phase is a Mott insulator with poor conductivity (also the conductivity of the semiconductor electrodes is significantly lower than that of metallic counter electrode), which limits its quantum efficiency in PEC processes to very small values. This is an inefficient photoelectrode, and it is well known that dopants can render it either n-type or p-type to increase the light-to-hydrogen conversion efficiency significantly. ${ }^{49}$

\section{Doped Hematite Thin Films}

Doping facilitates the movement of charges. Two doping approaches can help to optimize the PEC performance of a device. The n-type doping is done by introducing pentavalent (Group V) atoms into the lattice, and shifting the Fermi level upwards. Common n-type dopants are phosphorus $(\mathrm{P})$, arsenic (As) or antimony $(\mathrm{Sb})$ because these pentavalent atoms have one extra electron in the valence band.

Shinar and Kennedy ${ }^{50}$ reported the effect of doping in hematite with $\mathrm{ZrO}_{2}, \mathrm{CeO}_{2}, \mathrm{~V}_{2} \mathrm{O}_{5}, \mathrm{Nb}_{2} \mathrm{O}_{5}$, and $\mathrm{Al}_{4} \mathrm{C}_{3}$ using conventional powder processing. Their studies revealed that the best performance was not possible at low doping levels due to the formation of a large depletion layer width and consequently, to higher quantum efficiency; but for the optimal level of doping, the performance was found to differ according to the dopant. In their studies, $\mathrm{Al}_{4} \mathrm{C}_{3}$ showed better results due to the formation of $\mathrm{Fe}^{2+}$ in hematite. Others have attributed the improved efficiency of hematite $\mathrm{PE}$ due to $\mathrm{Fe}_{3} \mathrm{O}_{4}$ on its surface. A previous study claimed that because $\mathrm{Fe}^{2+}$ donor centers provide electrons due to thermal excitation. $\mathrm{Fe}^{3+}$ can be substituted with $\mathrm{Al}^{3+}, \mathrm{Co}^{3+}$ and $\mathrm{Cr}^{3+}$. The amount that can be substituted is determined by the difference in ionic radii and the valence of cations. The advantage of iso-morphous cationic substitution in hematite is that it allows tailoring and improving the electrical and semiconducting properties of hematite. Doping is not limited to other trivalent cations, such as $\mathrm{Mn}, \mathrm{Cu}$ and $\mathrm{Ni}$; other cations 
such as $\mathrm{Ge}^{4+}, \mathrm{Si}^{4+}$ and $\mathrm{P}^{5+}$ can also be used as dopant.

The conductivity of hematite PE increases due to the dopants leading to improved PEC performance. Several mechanisms have been discussed. The introduction of lattice strain by substituting smaller ionic radius cations in the place of $\mathrm{Fe}^{3+}$ decreases the $\mathrm{Fe}-\mathrm{O}$ distance, which induces the breakdown of d-electron correlation, leading to the collapse of magnetic ordering, resulting in the onset of the insulator to metal transition due to closing of the d-d or p-d gap. This type of increased conductivity has been reported for $\mathrm{Al}^{3+}$ doping. In many cases, however, the improved conductivity, hence PEC performance has been attributed to the preferential ordering of crystallites and/or lattice distortions. The change in structural symmetry and easier spin-forbidden transitions has been suggested to contribute to the improved performance of hematite $\mathrm{PE}^{51}$

In case of $\mathrm{Ti}^{-4+}$-doped hematite, the increased conductivity is due to the substitution of $\mathrm{Ti}^{-4+}$ at $\mathrm{Fe}^{3+}$ sites forming $\mathrm{Fe}^{2+}$ to maintain the average charge per three cations. $\mathrm{Fe}^{2+}$ then acts as a donor center with respect to the surrounding $\mathrm{Fe}^{3+}$ and provides electrons to $\mathrm{Fe}^{3+}$ under thermal excitation. Therefore, an electric current could be created under the influence of an external electric field. One more explanation is that tetravalent ions may introduce electrons to the conduction band of the semiconductor PE and the localized electrons can produce electric current under the influence of a potential gradient. These mechanisms are similar to the mechanism that has been suggested for the improved conductivity in thermally-reduced hematite samples. Thermal reduction would result in the production of oxygen vacancies in the hematite lattice. $^{52}$ The ionization of oxygen vacancies would result in either the introduction of electrons into the conduction band or the formation of electrons, which would reduce $\mathrm{Fe}^{3+}$ to $\mathrm{Fe}^{2+}$. Note that the role of dopants is not limited only to the increased conductivity. Doping in hematite promotes the band bending, which significantly increases the carrier density as well as the surface state results in the pronounced photocurrent density as compared to undoped. ${ }^{53}$

The preparation of hematite thin films can be carried out using a range of methods, i.e., spray pyrolysis, ${ }^{54}$ chemical vapor deposition (CVD) ${ }^{55}$ low-pressure metallorganic chemical vapor deposition (MOCVD) ${ }^{56}$ plasma-enhanced chemical vapor deposition (PECVD), ${ }^{57}$ electrodeposition, ${ }^{58}$ dip coating, ${ }^{59}$ and SILAR. ${ }^{60}$ Irrespective of the method of preparation, hematite always exhibits n-type electrical conductivity because of the tendency of $\alpha-\mathrm{Fe}_{2} \mathrm{O}_{3}$ to become oxygen deficient. In addition, this semiconducting oxide possesses a high doping level with a concentration of majority carriers, $\mathrm{N}_{\mathrm{D}}$, reaching values of $10^{19}-10^{22} \mathrm{~cm}^{-3} 58$

\subsection{Ge and $\mathrm{Pb}$ doping}

Earlier studies on the PEC activity of doped $\alpha-\mathrm{Fe}_{2} \mathrm{O}_{3}$ by IV-A group elements was reported by Kennedy et al. ${ }^{61}$. The hematite anodes were prepared from $99.999 \%$ pure $\mathrm{Fe}_{2} \mathrm{O}_{3}$ and dopant materials, such as $\mathrm{GeO}_{2}$, $\mathrm{SnO}_{2}$ and $\mathrm{PbO}_{2}{ }^{62}$ High purity un-doped $\alpha-\mathrm{Fe}_{2} \mathrm{O}_{3}$ electrodes were highly resistive and did not exhibit any photo response. In case of $\mathrm{Ge}^{4+}$ doping, a low doping level of 0.002-0.01 a/o resulted in higher photocurrent densities at $0 \mathrm{~V} v s$. SCE but, at high $(>1 \mathrm{a} / \mathrm{o})$ doping levels. The results obtained for the $\mathrm{Pb}$ doped electrodes were difficult to explain because the $\mathrm{PbO}$ doped electrodes exhibited similar behavior to those for $\mathrm{PbO}_{2}$, i.e., n-type instead of the expected p-type. Finally, it was concluded that for a better PEC response, low doping was found to be essential and $\mathrm{Pb}^{4+}$ was present in trace amounts responsible for the n-type behavior.

\subsection{Zr doping}

The $\mathrm{Zr}$-doped $\alpha-\mathrm{Fe}_{2} \mathrm{O}_{3}$ nanostructured hematite thin films prepared by electrodeposition exhibited a marginal red shift in the absorption band edge. ${ }^{54}$ Because $\mathrm{Zr}$ doping in hematite did not show any significant change in the bandgap, it suggests that $\mathrm{Zr}$ doping does not produce any intermediate level within the energy level of iron oxide thin film. A sharp decrease in resistivity of $\mathrm{Zr}$-doped samples compared to the undoped samples, also accounts for the better performance of the samples upon doping. In brief, the enhancement in photocurrent was attributed to the improved conductivity by the substitution of $\mathrm{Fe}^{3+}$ with $\mathrm{Zr}^{4+}$ in the hematite lattice and higher value of the flat band potential.

\subsection{Cd doping}

The overall optical absorbance decreased with increasing Cd content in $\mathrm{Fe}_{2} \mathrm{O}_{3}$ film. This might be due to several factors, such as the scattering effect of hematite particles with different particle sizes depending on the $\mathrm{Cd}$ content. The decreases in high photon-to-current efficiency were attributed to photon-confinement and multiple scattering of incident photons inside the hematite film. The photocurrent increased with increasing annealing temperature. $\mathrm{Cd}$ incorporation in hematite enhances the photocurrent generation compared to bare hematite. The incorporated $\mathrm{Cd}(\mathrm{II})$ was speculated to exist as $\mathrm{CdO}$ and/or $\mathrm{Cd}(\mathrm{OH})_{2}$, which increase the conductivity of hematite and play electrocatalytic and photo-electrocatalytic roles. ${ }^{63}$ An alternative effect of $\mathrm{Cd}$ incorporation is likely to increase the photocurrents by ca. $60 \%$ than that of bare hematite. ${ }^{64}$

\subsection{Ti doping}

Ti-doped hematite is a potential key photoanode material, which despite its optimal band gap, excellent chemical stability, abundance, nontoxicity and low cost. ${ }^{65}$ The films prepared by sol-gel method with Ti doping showed the best PEC performance and stability with a negligible corrosive current under dark. Ferric chloride as an iron precursor exhibited slightly better PEC performance than ferric nitrate, possibly due to the different microstructures from different iron precursors. Due to calcination, the crystallinity improved results in improving the PEC performance. $^{66}$

Improvement in the photocurrent density with reduction in the band gap energy and electron-hole recombination leads to the significant increase in the performance for Ti-doped hematite was observed. ${ }^{67}$ Calcination creates photoactive surface sites with $\mathrm{Ti}^{4+}$ doped hematite. $\mathrm{Ti}^{-4+}$ doping in $\mathrm{Fe}_{2} \mathrm{O}_{3}$ enhances the photocurrent without increase in $\mathrm{N}_{\mathrm{D}}$. The increase in photocurrent cannot be explained only by the decrease in bulk recombination, because the dependence of the photocurrent of the $\mathrm{Ti}^{-4+}$-doped $\mathrm{Fe}_{2} \mathrm{O}_{3}$ electrode on their calcinations. ${ }^{68}$ The excess $\mathrm{d}$ electron with $\mathrm{Fe}^{2+}$ acts as a donor. ${ }^{69}$ The photocurrent density drastically increases with sintering temperature for Ti doped hematite. The improved photocurrent by increased sintering temperature can be attributed to different factors such as a reduced defect density, improved contact at the interface of hematite and the substrate and/or the enhanced photoactivity by Sn diffusion from FTO substrate. The high plateau photocurrent density and IPCE can be attributed to the Ti doping, which increase the effective surface area, reduce the electronhole recombination and reduce the electron-hole recombination at the time scale beyond a few picoseconds, and increase the donor density in hematite. $^{70}$

Lian et al. reported the enhanced PEC performance of $\mathrm{Ti}_{\mathrm{Fe}} \mathrm{O}_{3}$ thin films prepared by the sol-gel method. The IPCE showed a value of $32.6 \%$ at zero bias vs. SCE, at $400 \mathrm{~nm}$. This is possibly because titanium oxide forms on the surface of the hematite. Each $\mathrm{Ti}^{4+}$ ion in the lattice can donate a free electron, which results in an increase in the conductivity of the thin film and makes the excited electrons and holes 
survive longer (i.e., more carrier life time) rather than recombine rapidly as hematite (un-doped). ${ }^{71}$ Pulsed laser deposited hematite with $3 \mathrm{~mol} \%$ Ti-doped film exhibited the highest relative PEC performance. ${ }^{72}$ This is understood to be due to the favorable crystallinity and Ti doping, that reduce the electron-hole recombination and increase the donor density in hematite films. ${ }^{73}$ In other report, preparation of Ti-doped hematite using hydrothermal method followed by sintering of deposited film was employed to obtain nanostructures with the urchin-like morphology. The highest IPCE measured for Ti-doped sample is about $60 \%$ (at a wavelength of $350 \mathrm{~nm}$ ) which is attributed to be due to reduced electron-hole recombination with an urchin-like morphology and improved donor density by Ti doping..$^{70}$

\subsection{Si doping}

Si-doping affected the grains size, leading to a decrease in grain width. The lattice parameter calculation showed that there was no deformation of the lattice due to $\mathrm{Si}$ doping. This indicates $\mathrm{Si}$ on the grain surface. A previous study suggested that Si-doping preferentially segregated on the surface of the (300) plane, i.e., allowing grains growth to occur preferentially in the (110) plane, leading to a worm like shape. ${ }^{74}$ The indirect transition was identified as a spin-forbidden $\mathrm{Fe}^{3+} 3 \mathrm{~d} \rightarrow 3 \mathrm{~d}$ excitation, whereas the direct transition corresponded to $\mathrm{O}^{2-} 2 \mathrm{p} \rightarrow \mathrm{Fe}^{3+}$ $3 \mathrm{~d}$ charge transfer. Silicon-doping results in a different phase of the $\mathrm{Fe}_{2} \mathrm{O}_{3}$ (maghemite). The photo-electrochemical activity demonstrates that the photocurrent measured with Si-doped maghemite fibres is $53 \%$ higher with respect to that of pure hematite fibres, as an effect of the nearly threefold increase in the donor concentration brought about by doping. This, in turn, improves the charge transfer at the interface, leading to a higher charge injection from the electrode to the electrolyte and, thus, to a greater photo-oxidation efficiency. ${ }^{75}$

Silicon doping decreases the particle size even further. ${ }^{76}$ The electrical conductivity was up to 4 orders of magnitude higher along the (001) basal plane than perpendicular to it. ${ }^{77}$ The vertical orientation of crystallites and the conducting (001) planes in the films might be one of the reasons for the high water-splitting efficiencies obtained. The enhanced photo response by silicon doping can be understood in terms of four different proposed mechanisms. (1) Due to the substitution of $\mathrm{Fe}^{3+}$ by $\mathrm{Si}^{4+}$ in the hematite lattice, silicon acts as electron donor thereby improving the electrical conductivity. ${ }^{50}$ (2) Silicon doping decreases the particle size, which can be explained by the perturbation of hematite lattice growth due to the smaller ionic radius of $\mathrm{Si}^{4+}$ compared to $\mathrm{Fe}^{3+}$. The presence of silicon decreases the grain size to a level that is comparable to the hole diffusion length of only a few nanometers in hematite. This makes the possible hole capture by a surface site competitive with recombination, even without the electrical field of a space charge layer. (3) In addition, the smaller grain size increases the specific surface area of the PE. Assuming that overall oxygen evolution is limited by a surface reaction step, this can contribute to the higher water oxidation efficiency by the increased number of active surface sites per unit of substrate area. (4) The leaching of silicon from the $\mathrm{Fe}_{2} \mathrm{O}_{3}$ surface by the $1 \mathrm{M} \mathrm{NaOH}$ electrolyte might activate the surface, even on the atomic scale, by creating $\mathrm{Fe}^{3+}$ surface sites with additional dangling bonds. ${ }^{78}$

The crystallite sizes in the film were found to depend strongly on the temperature and the presence of a silicon dopant precursor (Tetraethyl orthosilicate). The formation of an electric field due to ntype doping can be responsible for the improved photocurrent. The improved conductivity induced by the incorporation of the dopant is most likely from the n-type lattice substitution of $\mathrm{Fe}^{3+}$ by $\mathrm{Si}^{4+}$, resulting in a higher electron concentration. From these studies, it was concluded that an unusually high doping density could be an important design strategy for solar water splitting by nanostructured PE because the of formation of a space-charge field inside the nanocrystallites of the polycrystalline PE, a factor that could play a major role in the separation of charges and enhancement of performance, even in the surface crystallites of $5 \mathrm{~nm}$.

\subsection{C doping}

The MWCNTs in contact with the $\mathrm{Fe}_{2} \mathrm{O}_{3}$ particles assisted effective charge transport from the $\mathrm{Fe}_{2} \mathrm{O}_{3}$ layer to the FTO surface and naturally promoted charge separation over the entire electrode. The role of the MWCNTs as an expressway for charge transport was clearly demonstrated. ${ }^{79}$ In addition, the charge carrier density was increased ca. 47 times for the $\mathrm{Fe}_{2} \mathrm{O}_{3}$-MWCNTs PEs similar to ZnO-MWCNTs PE. ${ }^{80}$ The results of Mott-Schottky showed that the flat band potential was shifted to a more positive potential for $\mathrm{Fe}_{2} \mathrm{O}_{3}$-MWCNTs, PEs.

Frites et al. ${ }^{81}$ reported that for $\mathrm{n}-\mathrm{Fe}_{2} \mathrm{O}_{3}$ nanowires, the effect of its high resistivity was minimized by reducing the transport distance of the photogenerated carriers to species in electrolyte solution (e.g., $\mathrm{OH}^{-}$ions) and its optical and electrical behavior were modified by the incorporation of carbon in its lattice. A photoelectrode of CM:n- $\mathrm{Fe}_{2} \mathrm{O}_{3}$ exhibited a two fold increase in photocurrent density at $0.0 \mathrm{~V} / \mathrm{SCE}$. This was attributed to carbon incorporation in $\mathrm{n}-\mathrm{Fe}_{2} \mathrm{O}_{3}$, resulting in an increase in conductivity.

\subsection{Pt doping}

Co-electrodeposition in cyclic voltammogram deposition techniques have been employed for doping $\alpha-\mathrm{Fe}_{2} \mathrm{O}_{3}$ with approximately 30 dopants, such as $\mathrm{Al}, \mathrm{Zn}, \mathrm{Cu}, \mathrm{Ni}, \mathrm{Co}, \mathrm{Cr}, \mathrm{Mo}, \mathrm{Ti}$, Pt, etc. The PEs, those doped with $\mathrm{Al}, \mathrm{Ti}, \mathrm{Pt}$, and Mo, exhibited the most promising results. The overall energy efficiency of $\sim 3 \%$ was observed for doped sample, which was approximately four times higher than that of the undoped samples. ${ }^{82}$

The Pt-doped samples exhibited electroactivity at a low potential range of -0.10 to $0.10 \mathrm{~V}$ but the current density was rather low. However, the Pt-doped iron oxide thin films showed a much higher photocurrent at a higher potential than that of the undoped samples. This was attributed to role of Pt in hematite behaving in three different ways. First, Pt acts as an electron donor due to the substitution of $\mathrm{Fe}^{3+}$ by $\mathrm{Pt}^{4+}$. The increased donor concentration in n-type doping would translate into an improvement in conductivity and enhanced charge transfer while decreasing the carrier recombination. Second, the increased donor concentration would increase the electric field across the space charge layer, resulting in the higher charge separation efficiency. Increasing the donor concentration; however, would reduce the width of the space charge layer and $\mathrm{Pt}^{4+}$ would have defect scattering recombination properties, which at high concentrations, would decrease the increased separation efficiency. Third, the more compact doped films may have greater electrical interconnectivity, which would facilitate charge transfer.

\subsection{Sn doping}

It was observed that the specific resistance is dependence on the Sn concentration, which is characteristic of the hopping mechanism for conductivity. It was also observed that the band gap increases with Sndoping. The electron conductivity was caused by the occurrence of bivalent ions, $\mathrm{Fe}^{+2}$. Electrons located on such ions as free electrons were considered impossible because they being in an excess negative charge in the $\mathrm{Fe}_{2} \mathrm{O}_{3}$ lattice, are bound to ions $\mathrm{Sn}^{+4}$ by electrostatic forces. In addition, the Sn-doping level has a remarkable effect on the flat band 
potential of $\mathrm{Fe}_{2} \mathrm{O}_{3}$ electrode. ${ }^{83}$

A photocurrent density of $\mathrm{Sn}$ doped hematite is 3 times higher than that of bare hematite which is leads to improved electrical conductivity for Sn doped hematite, the efficient electron transport pathway by TCO and the increased surface area by hierarchically branched structure. The carrier density increases with Sn doping which served as an electron donor. $^{84}$

\subsection{Ir doping}

Chronoamperometry revealed a slight decrease in photocurrent due to the detachment of $\mathrm{IrO}_{2}$ particles from the PE surface. As there were no organic stabilizing ligands present for consumption, the photocurrent was attributed solely to water oxidation. Despite applying the best OER catalyst to hematite and observing an unprecedented photocurrent under standard conditions, the onset of the photocurrent was observed at a voltage of $400 \mathrm{mV}$, which is positive than the flat-band potential, suggesting that surface states with mid band-gap energies facilitate carrier recombination in $\mathrm{Fe}_{2} \mathrm{O}_{3}{ }^{85}$

\section{Conclusions}

As the dopant concentration increases, above $\sim 0.1$ to $1 \%$, it is common practice to refer to the materials as solid solutions rather than doped materials. Solid solutions can be divided into two types, i.e., substitutional solid solutions, where the atom or ion that is being introduced directly replaces an atom or ion of the same charge in the parent structure, and an interstitial solid solution, in which the introduced species occupies a site that is normally empty and no ions or atoms are left out. Stoichiometric hematite is an n-type semiconductor. In n-type hematite, the conduction band is comprised of empty $\mathrm{Fe}^{3+} \mathrm{d}$ orbitals while the valence band is composed of full two Fe $3 \mathrm{~d}$ ligand field orbitals and some admixture from the $\mathrm{O}$ antibonding $2 \mathrm{p}$ orbitals. ${ }^{47}$

Divalent doping offers p-type conductivity, whereas quadrivalent doping results in n-type conductivity for hematite thin films. This review presented the studies on the PEC response of $\mathrm{Ge}^{4+}, \mathrm{Pb}^{4+}, \mathrm{Zr}^{4+}$, $\mathrm{Cd}^{4+}, \mathrm{Sn}^{4+}, \mathrm{Pt}^{4+}, \mathrm{Ir}^{4+}, \mathrm{C}^{4+}, \mathrm{Ti}^{4+}$, and $\mathrm{Si}^{-4}$. In general, dopants improve the conductivity of hematite thin films. The improved conductivity brought on the incorporation of the dopant is most likely from the n-type lattice substitution of $\mathrm{Fe}^{3+}$ by tetravalent ions, such as $\mathrm{Si}^{4+}$, resulting in a higher electron concentration. The results of $\mathrm{Si}^{4+}$ are promising, mainly due to the observed microstructural change. The nanocrystallites oriented perpendicular to the substrate of an appropriate size under optimized dopant concentrations may be considered responsible for obtaining the desired current and voltage necessary for water splitting when supplemented. This supplementation may be carried out by employing a Tandem cell configuration. This induces a proper direction for the future course of investigations that may lead to an economic, renewable method for eco-friendly hydrogen production.

\section{Acknowledgements}

Authors are thankful to University with Potential for Excellence (UPE)-II, University Grants Commission, New Delhi, India for financial support. PKB is thankful to University Grants Commission, New Delhi, India for the award of Dr. D. S. Kothari Post Doctoral Fellowship and financial assistance (PH/16-17/0074).

\section{References:}

1. T. Bak, J. Nowotny, M. Rekas and C. C. Sorrell, Int. J. Hydrogen Energ., 2002, 27, 991-1022.

2. A. J. Bard and M. A. Fox, Acc. Chem. Res., 1995, 28, 141-145.

3. S. Y. Tee, K. Y. Win, W. S. Teo, L. D. Koh, S. Liu, C. P. Teng and M. Y. Han,
Adv. Sci., 2017, 4, 1600337

4. N. S. Lewis, Nature, 2001, 414, 589-590.

5. M. E. El-Khouly, E. El-Mohsnawy and S. Fukuzumi, J. Photochem Photobiol. C. Photochem. Rev., 2017, 31, 36-83.

6. K. Rajeshwar, J. Appl. Electrochem., 2007, 37, 765-787.

7. R. Van de Krol, Y. Q. Liang and J. Schoonman, J. Mater. Chem., 2008, 18, 2311-2320.

8. Y. Li, W. L. Zhou and Z. L. Wang, Three-Dimensional Nanoarchitectures, Springer Science+Business Media, LLC outside the People's Republic of China, 2011, 133.

9. A. Fujishima and K. Honda, Nature, 1972, 238, 37-38.

10. W. Fang, M. Xing and J. Zhang, J. Photochem. Photobiol. C Photochem. Rev., 2017, 32, 21-39.

11. A. Wolcott, W. A. Smith, Y. P. Zhao and J. Z; Zhang, Adv. Funct. Mater. 2009, 19, 1849-1856.

12. A. Wolcott, T. R. Kuykendall, W. Chen, S. Chen and J. Z. Zhang, J. Phys Chem. B, 2006, 110, 25288-25296.

13. M. Manikandan, T. Tanabe, P. Li, S. Ueda, G. V. Ramesh, R. Kodiyath, J. Wang, T. Hara, A. Dakshanamoorthy, S. Ishihara, K. Ariga, J. Ye, N. Umezawa and H. Abe, ACS Appl. Mater. Interfaces, 2014, 6, 3790-3793.

14. P. Dias, A. Vilanova, T. Lopes, L. Andrade and A. Mendes, Nano Energy, 2016, 23, 70-79.

15. Gurudayal, S. Y. Chiam, M. H. Kumar, P. S. Bassi, H. L. Seng, J. Barber and L. H. Wong, ACS Appl. Mater. Interfaces, 2014, 6, 5852-5859.

16. H. Gao, C. Liu, H. E. Jeong and P. Yang, ACS Nano, 2012, 6, 234-240.

17. S. Wu, C. H. Cheng, Y. J. Hsiao, R. C. Juang and W. F. Wen, Renew. Sust. Energ. Rev., 2016, 58,574-580.

18. J. Nowotny, C. C. Sorrell, T. Bak and L. R. Sheppard, Sol. Energy, 2005, 78,593-602.

19. P. Tseng and J. Lee, P. Friley, Energy, 2005, 30, 2703-2720.

20. J. Nowotny, C. C. Sorrell and L. R. Sheppard, Int. J. Hydrogen Energ., 2005, 30, $521-544$

21. N. Armaroli and V. Balzani, Angew. Chem., Int. Ed., 2007, 46, 52-66.

22. P. K. Farsoiya, A. D. Prasad International Journal of Engineering Research and Applications (IJERA) ISSN: 2248-9622 National Conference on Advances in Engineering and Technology, 2014, 26-30.

23. J. Gan, X. Lu and Y. Tong, Nanoscale, 2014, 6, 7142-7164.

24. N. Serpone, A. V. Emeline, V. K. Ryabchuk, V. N. Kuznetsov, Y. M. Artemev and S. Horikoshi, ACS Energy Lett., 2016, 1, 931-948

25. F. Rodriguez-Hernandez, D. C. Tranca, A. Martinez-Mesa, L1. Uranga-Pina and G. J. Seifert, Phys. Chem. C, 2016, 120, 25851-25860.

26. M. G. Walter, E. L. Warren, J. R. McKone, S. W. Boettcher, Q. Mi, E. A. Santori and N. S. Lewis, Chem. Rev., 2010, 110, 6446-6473.

27. R. Ali and A. Pasha, IOP Conf. Series: Materials Science and Engineering, 2018, 376, 012103 .

28. C. C. Sorrell, J. Nowotny and S. Sugihara, Materials for energy conversion devices. Cambridge England: Woodhead Publishing Limited; 2005.

29. J. Dufour, D. P. Serrano, J. L. Galvez, J. Moreno and A. Gonzalez, Energ. Fuel., 2011, 25, 2194-2202.

30. V. M. Aroutiounian, V. M. Arakelyan and G. E. Shahnazaryan, Sol. Energy, $2005,78,581-592$

31. A. Currao, Chimia, 2007, 61, 815-819.

32. M. F. Weber and M. J. Dignam, J. Electrochem. Soc., 1984, 131, 1258-1265.

33. M. D. Hernndez-Alonso, F. Fresno, S. Suarez and J. M. Coronado, Energy Environ. Sci., 2009, 2, 1231-1257.

34. K. Maeda and K. Domen, J. Phys. Chem. Lett., 2010, 1, 2655-2661.

35. A. J. Esswein and D. G. Nocera, Chem. Rev., 2007, 107, 4022-4047.

36. A. K. Singh, K. Mathew, H. L. Zhuang and R. G. Hennig, J. Phys. Chem. Lett., 2015, 6, 1087-1098.

37. S. U. M. Khan, M. Al-Shahry and W. B. Ingler, Science, 2002, 297, $2243-$ 2245.

38. Z. Chen, H. N. Dinh and E. Miller, Photoelectrochemical Water Splitting: Standards, Experimental Methods, and Protocols; Springer: New York, NY, 2013.

39. D. Kumar, H. Singh, S. Jouen, B. Hannoyer and S. Banerjee, RSC Adv., 2015, 5, 7138-7150

40. L. Machala, J. I. Tucek and R. Zboril, Chem. Mater., 2011, 23, 3255-3272.

41. J. D. Desai, H. M. Pathan, S. K. Min, K. D. Jung and O. S. Joo, Appl. Surf. 
Sci., 2006, 252, 2251-2258

42. L. Vayssieres and A. Manthiram, J. Phys. Chem. B, 2003, 107, 2623-2625.

43. J. Baltrusaitis, C. Hatch and R. Orlando, J. Phys. Chem. C, 2012, 116, 18847-18856.

44. http://www.geocities.jp/ohba_lab_ob_page/Structure/Hematite_bond.JPG

45. J. D. Desai, H. M. Pathan, S. K. Min, K. D. Jung and O. S. Joo, Appl. Surf. Sci., 2005, 252, 1870-1875.

46. http://wwwchem.uwimona.edu.jm/courses/CFT.html

47. R. M. Cornell and U. Schwertmann, The Iron Oxides: Structure, Properties, Reactions, Occurrence and Uses; VCH: New York 1996.

48. P. Hiralal, S. Saremi-Yarahmadi, B. C. Bayer, H. Wang, S. Hofmann, K. G. U. Wijayantha and G. A. Amaratunga, J. Sol. Energ. Mat. Sol. Cells, 2011, 95, 1819-1825.

49. I. Cesar, A. Kay, J. A. G. Martinez and M. Gratzel, J. Am. Chem. Soc., 2006, 128, 4582-4583.

50. R. Shinar and J. H. Kennedy, Sol. Energ. Mater., 1982, 6, 323-335.

51. A. Kleiman-Shwarsctein, M. N. Huda, A. Walsh, Y. Yan, G. D. Stucky, Y. S. Hu. M. M. Al-Jassim and E. W. McFarland, Chem. Mater., 2010, 22, 510517.

52. J. Mock, B. Klingebiel, F. Köhler, M. Nuys, J. Flohre, S. Muthmann, T. Kirchartz and R. Carius, Phys. Rev. Mater, 2017, 1, 065407.

53. D. Wang, H. Chen, G. Chang, X. Lin, Y. Zhang, A. Aldalbahi, C. Peng, J. Wang and C. Fan, ACS Appl. Mater. Interfaces, 2015, 7, 14072-14078.

54. M. Vanags, A. Sutka, J. Kleperis and P. Shipkovs, Ceram. Int., 2015, 41, 9024-9029.

55. T. Maruyama and T. Kanagawa, J. Electrochem. Soc., 1996, 143, 1675-1677.

56. K. Shalini, G. N. Subbanna, S. Chandrasekaran and S. A. Shivashankar, Thin Solid Films, 2003, 424, 56-60.

57. E. T. Lee, B. J. Kim and G. E. Jang, Thin Solid Films, 1999, 341, 73-78.

58. R. S. Schrebler, H. Altamirano, P. Grez, F. V. Herrera, E. C. Munoz, L. A. Ballesteros, R. A. Cordova, H. Gomez and E. A. Dalchiele, Thin Solid Films, 2010, 518, 6844-6852.

59. K. Maabong, A. G. J. Machatine, B. S. Mwankemwa, A. Braun, D. K. Bora, R. Toth and M. Diale, Phys B Condens Matter, 2018, 535, 67-71.

60. A. J. Abel, A. M. Patel, S. Y. Smolin, B. Opasanont and J. B. Baxter, J. Mater. Chem. A, 2016, 4, 6495-6504.

61. J. H. Kennedy, M. Anderman and R. Shinar, J. Electrochem. Soc., 1981, 128, 2371-2373.

62. J. H. Kennedy, R. Shinar and J. P. Ziegler, J. Electrochem. Soc., 1980, 127, 2307-2309.

63. A. Bak, S. K. Choi and H. Park, Appl. Cat. B: Env., 2011, 110, 207-215.

64. A. Bak, S. K. Choi and H. Park, Bull. Korean Chem. Soc., 2015, 36, $1487-$
1494.

65. M. Rioult, R. Belkhou, H. Magnan, D. Stanescu, S. Stanescu, F. Maccherozzi, C. Rountree and A. Barbier, Surf. Sci., 2015, 641, 310-313.

66. O. Latunde, Synthesis of nanostructured iron oxide thin films for photocatalytic hydrogen production, NNIN REU Research Accomplishments chemistry, 2008, 44-45.

67. A. Azad and S. J. Kim, Mater. Res. Bull., 2016, 84, 474-479.

68. F. Amano, B. Ohtani and H. Yoshida, J. Electroanal Chem., 2016, 766, 100106.

69. F. J. Morin, Phys. Rev. 1951, 83, 1005-1011.

70. J. Deng, J. Zhong, A. Pu, D. Zhang, M. Li, X. Sun and S. T. Lee, J. Appl. Phys., 2012, 112, 084312.

71. X. Lian, X. Yang, S. Liu, Y. Xu, C. Jiang and J. Chen, R. Wang, Appl. Surf. Sci., 2011, 258, 2307-2311.

72. T. Sh. Atabaev, M. Ajmal, N. H. Hong, H. K. Kim and Y. H. Hwang, Appl. Phys. A, 2015, 118, 1539-1542.

73. A. Pu, J. Deng, M. Li, J. Gao, H. Zhang, Y. Hao, J. Zhong and X. Sun, J. Mater. Chem. A, 2014, 2, 2491-2497.

74. F. L. Souza, K. P. Lopes, P. A. P. Nascente and E. R. Leite, Sol. Energ. Mat. Sol. Cells, 2009, 93, 362-368.

75. S. Santangelo, P. Frontera, F. Panto, S. Stelitano, M. Marelli, S. Patane, F. Malara, V. D. Santo and P. Antonucci, Int. J. Hydrogen Energ., 2017, 42, 28070-28081.

76. Y. Zhu and C. Li, Mater. Chem. Phys., 1997, 51, 169-173.

77. X. Wen, S. Wang, Y. Ding, Z. L. Wang and S. J. Yang, Phys. Chem. B, 2005, 109, 215-220.

78. R. Nakamura, T. Okamura, N. Ohashi, A. Imanishi and Y. Nakato, J. Am. Chem. Soc. 2005, 127, 12975-12983.

79. J. Y. Kim, H. Jun, S. J. Hong, H. G. Kim and J. S. Lee, Int. J. Hydrogen Energ., 2011, 36, 9462-9468.

80. W. D. Zhang, L. C. Jiang and J. S. Ye, J. Phys. Chem. C, 2009, 113, 1624716253.

81. M. Frites, Y. A. Shaban and S. U. M. Khan, Int. J. Hydrogen Energ., 2010, 35, 4944-4948.

82. E. W. McFarland, Y. S. Hu, A. K. Shwarsctein, P. Zhang and A. J. Forman, DOE Hydrogen Program, FY 2008 Annual Progress Report.

83. V. M. Aroutiounian, V. M. Arakelyan, G. E. Shahnazaryan, H. R. Hovhannisyan and H. Wang, J. A. Turner, Sol. Energy, 2007, 81, 1369-1376.

84. S. Park, H. J. Kim, C. W. Lee, H. J. Song, S. S. Shin, S. W. Seo, H. K. Park, S. Lee, D. W. Kim and K. S. Hong, Int. J. Hydrogen Energ., 2014, 39, 16459-16467.

85. S. D. Tilley, M. Cornuz, K. Sivula and M. Gratzel, Angew. Chem. Int. Ed., 2010, 49, 6405-6408. 